Systematic Study of the Properties of CdS Clusters

with Carboxylate Ligands using a Deep Neural

Network Potential Developed with Data from

\title{
Density Functional Theory Calculations
}

Kiet A. Nguyen, ${ }^{a, b *}$ Ruth Pachter, ${ }^{a}{ }^{*}$ and Paul N. Day ${ }^{a}$ 
Table S1. Relative energies (in $\mathrm{kcal} / \mathrm{mol}$ ) for $\mathrm{Cd}_{10} \mathrm{~S}_{4} \mathrm{X}_{12}(\mathrm{X}=$ acetate) isomers shown in Figure $5 \mathrm{~S})$.

\begin{tabular}{|l|c|c|}
\hline $\mathrm{Cd}_{10} \mathrm{~S}_{4} \mathrm{X}_{12}$ & $\mathrm{PBE0}-\mathrm{D}^{\mathrm{a}}$ & $\mathrm{MP}^{\mathrm{b}}$ \\
\hline $\mathbf{a}$ & 0.0 & 0.0 \\
\hline $\mathbf{b}$ & 5.4 & $9.1(9.4)$ \\
\hline $\mathbf{c}$ & 12.3 & $14.5(15.0)$ \\
\hline $\mathbf{d}$ & 12.9 & $16.8(13.6)$ \\
\hline $\mathbf{e}$ & 16.7 & $21.3(19.5)$ \\
\hline $\mathbf{f}$ & 39.2 & $37.9(39.2)$ \\
\hline $\mathbf{g}$ & 55.5 & $61.9(63.7)$ \\
\hline $\mathrm{MAE}$ & $3.7(3.1)$ & \\
\hline
\end{tabular}

aPBE0-D3/SD-6-31G(d)//PBE0-D3/SD-6-31G(d).

bMP2/SD-SD-6-31G(d)//PBE0-D3/SD-6-31G(d). MP2/def2-TZVP//PBE0-D3/SD-6-31G(d) values in parentheses. 
Table S2. Relative energies (in $\mathrm{kcal} / \mathrm{mol}$ ) for $\mathrm{Cd}_{10} \mathrm{~S}_{4} \mathrm{X}_{12}(\mathrm{X}=$ acetate) isomers shown in Figure $5 \mathrm{~S}$.

\begin{tabular}{|l|c|c|}
\hline $\mathrm{Cd}_{10} \mathrm{~S}_{4} \mathrm{X}_{12}$ & PBE0-D3 $^{\mathrm{a}}$ & PBE0-D3 $^{\mathrm{b}}$ \\
\hline $\mathbf{a}$ & 0.0 & 0.0 \\
\hline $\mathbf{b}$ & 5.4 & 10.1 \\
\hline $\mathbf{c}$ & 12.3 & 11.6 \\
\hline $\mathbf{d}$ & 12.9 & 13.7 \\
\hline $\mathbf{e}$ & 16.7 & 14.7 \\
\hline $\mathbf{f}$ & 39.2 & 33.6 \\
\hline g & 55.5 & 47.4 \\
\hline MAE & 3.6 & \\
\hline
\end{tabular}

aPBE0-D3/SD-6-31G(d)//PBE0-D3/SD-6-31G(d). bPBE0-D3/def2-TZV//PBE0-D3/def2-TZVP. 
Table S3. PBE0-D3 distortion energies ${ }^{\mathrm{a}}$ (in $\mathrm{kcal} / \mathrm{mol}$ ) for the $\mathrm{Cd}_{44} \mathrm{~S}_{26} \mathrm{X}_{44}$ cluster with different $\mathrm{X}$ ligands.

\begin{tabular}{|l|c|}
\hline Ligand & Energy $^{\mathrm{a}}$ \\
\hline Formate & -35.5 \\
\hline Acetate & -71.0 \\
\hline Propanoate & -67.3 \\
\hline Butanoate & -54.5 \\
\hline Octanoate & -22.8 \\
\hline
\end{tabular}

${ }^{a}$ Energy relative to the tetrahedral structure with $T$ symmetry as computed at the PBE0-D3/SD-631G(d)//PBE0-D3/SD-6-31G(d) level. 


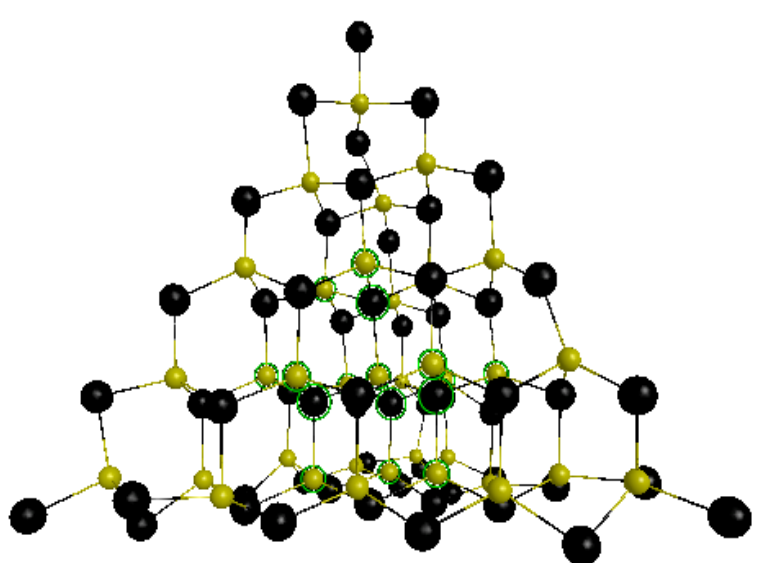

(a)

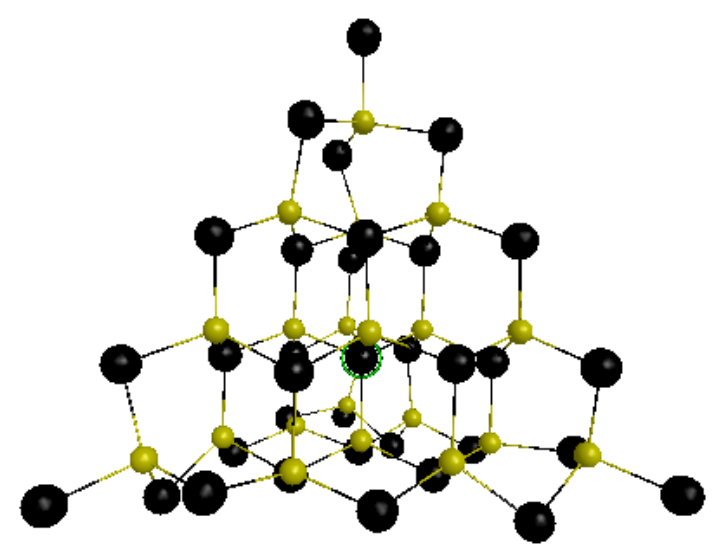

(c)

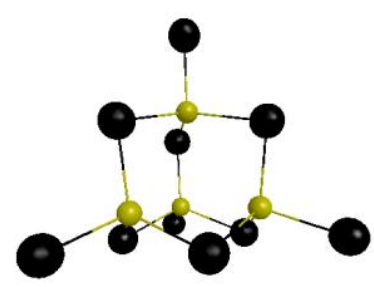

(e)

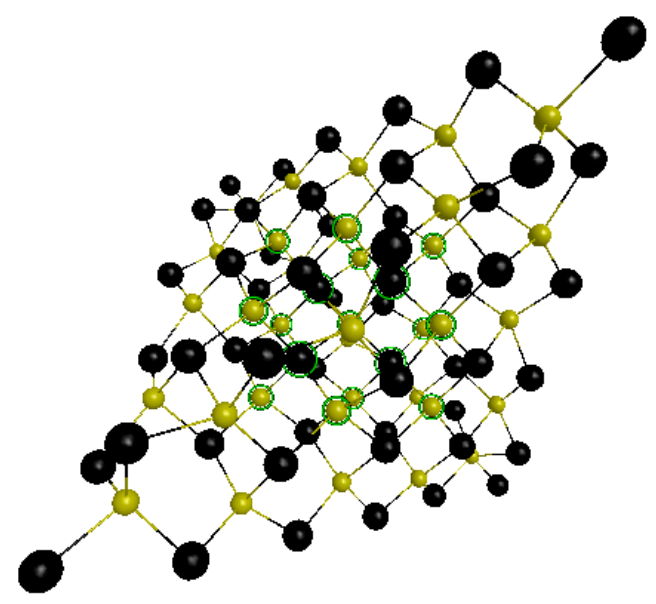

(b)

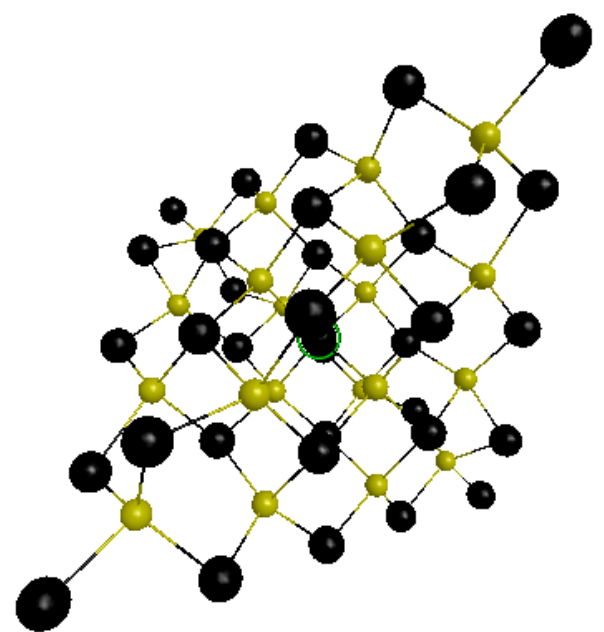

(d)

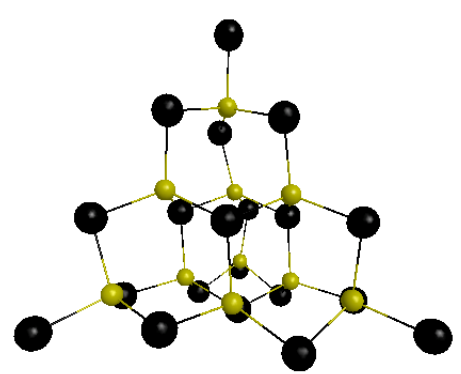

(f)

Figure S1. Side and top views of the $\mathrm{T} 5 \mathrm{Cd}_{56} \mathrm{~S}_{35}(\mathrm{a}, \mathrm{b}), \mathrm{T} 4 \mathrm{Cd}_{35} \mathrm{~S}_{20}(\mathrm{c}, \mathrm{d})$ cluster structures and structures of the $\mathrm{T} 2 \mathrm{Cd}_{10} \mathrm{~S}_{4}$ (e) and $\mathrm{T} 3 \mathrm{Cd}_{20} \mathrm{~S}_{10}$ (f) clusters. $\mathrm{T} 5 \mathrm{Cd}_{35} \mathrm{~S}_{20}$ has an anti $\mathrm{C} 1 \mathrm{Cd}_{4} \mathrm{~S}_{13}$ core, shown with green circles. The tetra-coordinated $\mathrm{Cd}$ (black) core atom of $\mathrm{T} 4 \mathrm{Cd}_{35} \mathrm{~S}_{20}$ is shown with a green circle. 


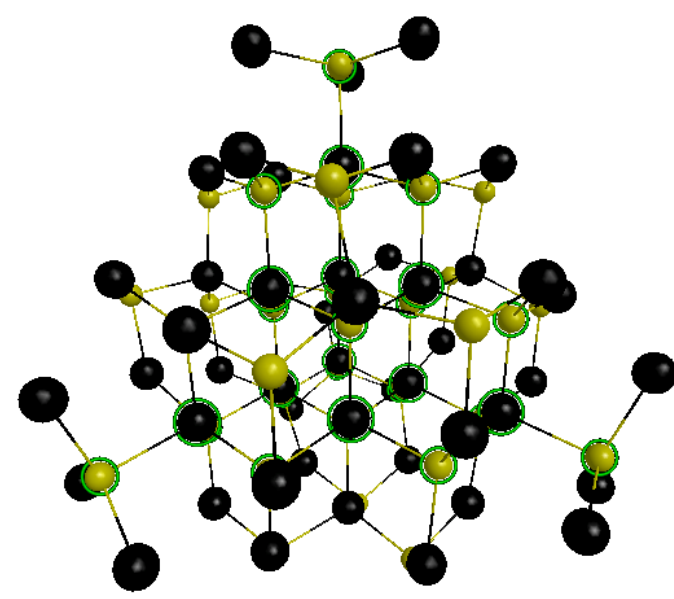

(a)

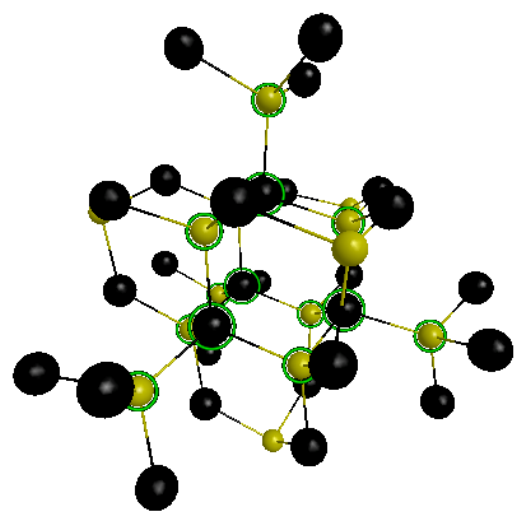

(c)

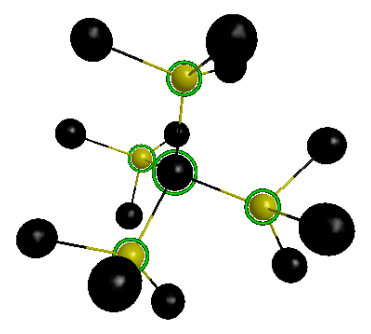

(e)

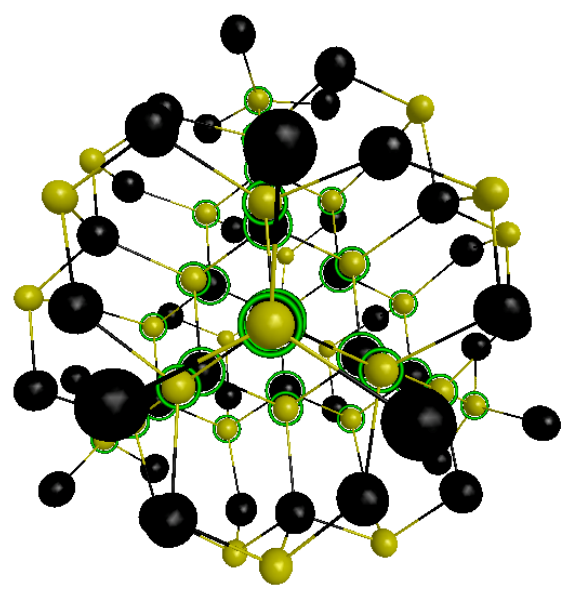

(b)

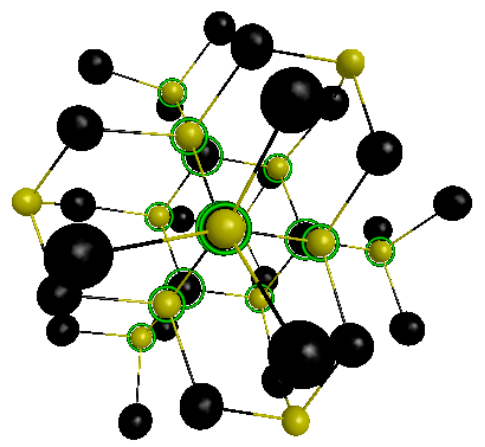

(d)

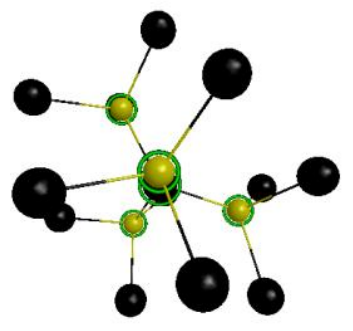

(f)

Figure S2. Side and top views of the $\mathrm{C} 3 \mathrm{Cd}_{50} \mathrm{~S}_{32}(\mathrm{a}, \mathrm{b}), \mathrm{C} 2 \mathrm{Cd}_{28} \mathrm{~S}_{14}(\mathrm{c}, \mathrm{d})$ and $\mathrm{C} 1 \mathrm{Cd}_{13} \mathrm{~S}_{4}(\mathrm{e}, \mathrm{f})$ cluster structures. The $\mathrm{C} 3 \mathrm{Cd}_{50} \mathrm{~S}_{32}$ has an anti-T3 $\mathrm{Cd}_{10} \mathrm{~S}_{20}$ core, while the $\mathrm{C} 2 \mathrm{Cd}_{28} \mathrm{~S}_{14}$ and $\mathrm{C} 1$ $\mathrm{Cd}_{13} \mathrm{~S}_{4}$ clusters have anti-T2 $\mathrm{Cd}_{4} \mathrm{~S}_{10}$ and an anti-T1 $\mathrm{CdS} 4$ cores, respectively. Inner core $\mathrm{Cd}$ (black) and $\mathrm{S}$ (yellow) atoms are labeled with green circles. 


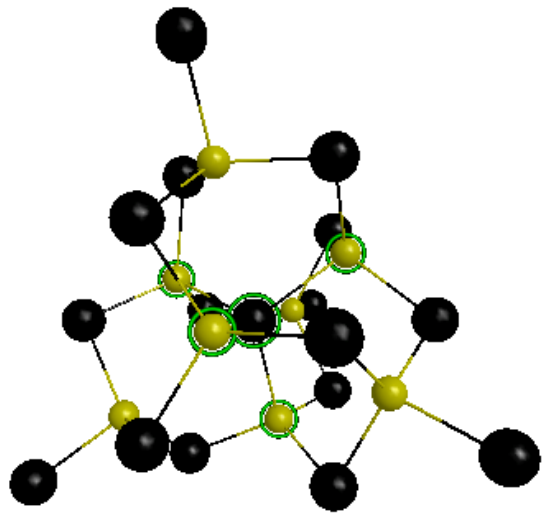

(a)

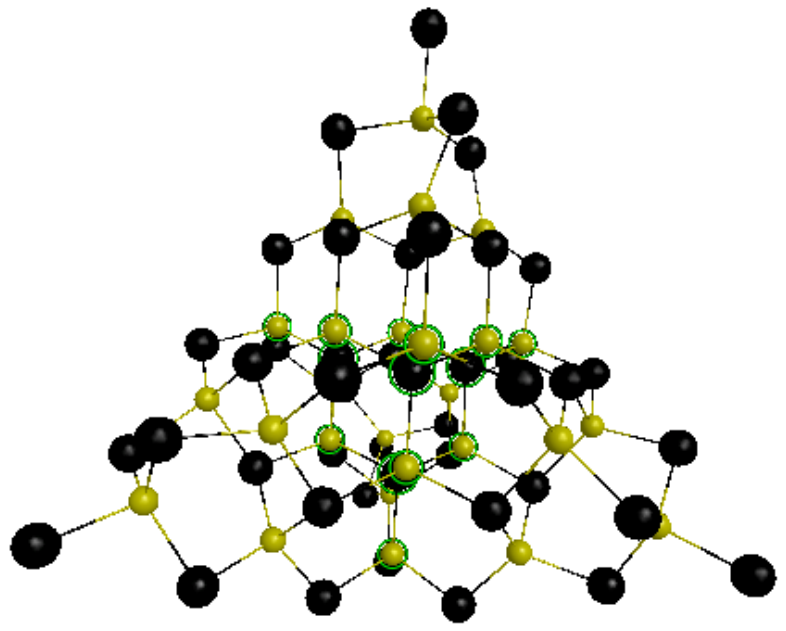

(c)

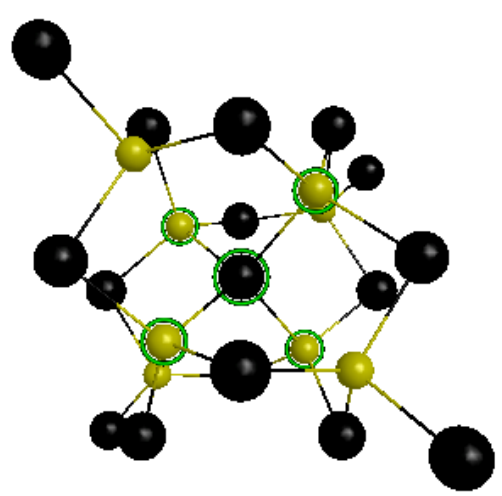

(b)

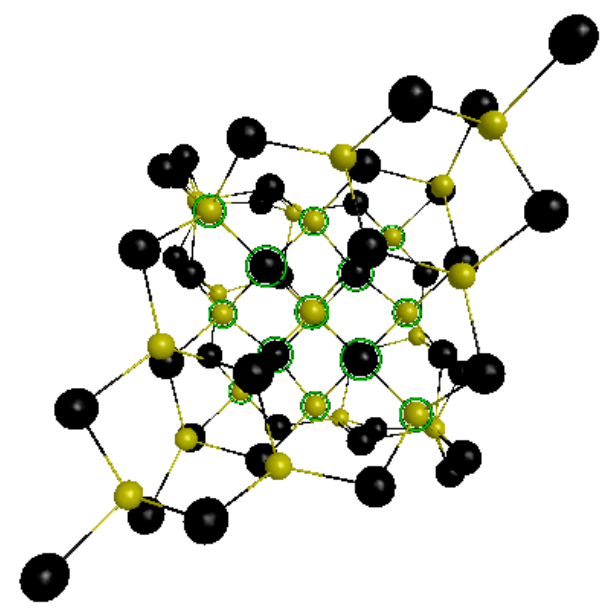

(d)

Figure S3. Side (a) and top (b) views of the $\mathrm{P} 1 \mathrm{Cd}_{17} \mathrm{~S}_{8}$ structures. Side (c) and top (d) views of the $\mathrm{P} 2 \mathrm{Cd}_{44} \mathrm{~S}_{26}$ cluster structures. The $\mathrm{P} 1 \mathrm{Cd}_{17} \mathrm{~S}_{8}$ cluster has an anti-T1 $\mathrm{CdS} 4$ core while the $\mathrm{P} 2$ $\mathrm{Cd}_{44} \mathrm{~S}_{26}$ has an anti-T2 $\mathrm{Cd}_{4} \mathrm{~S}_{10}$ core. Inner core $\mathrm{Cd}$ (black) and $\mathrm{S}$ (yellow) atoms are shown with green circles. 


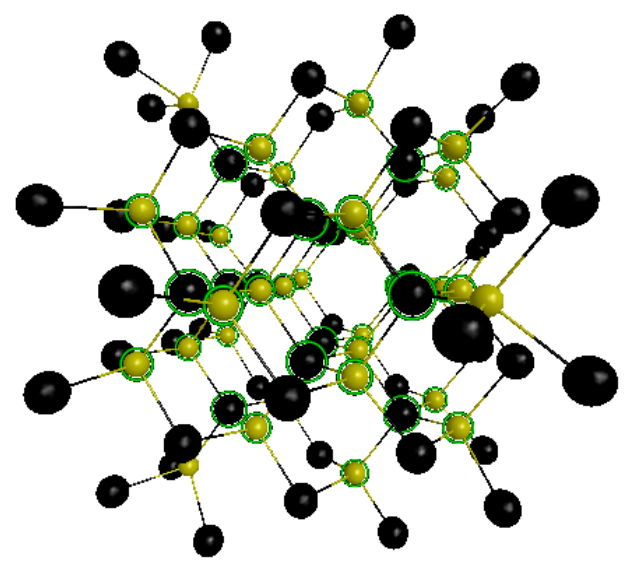

(a)

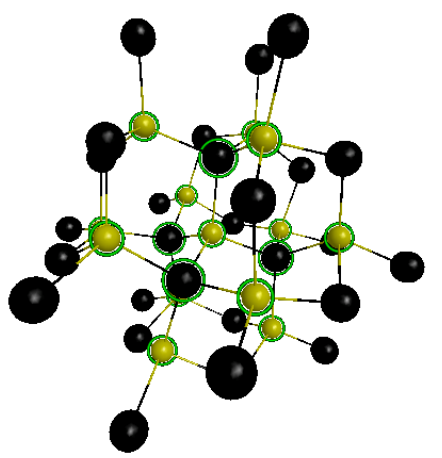

(c)

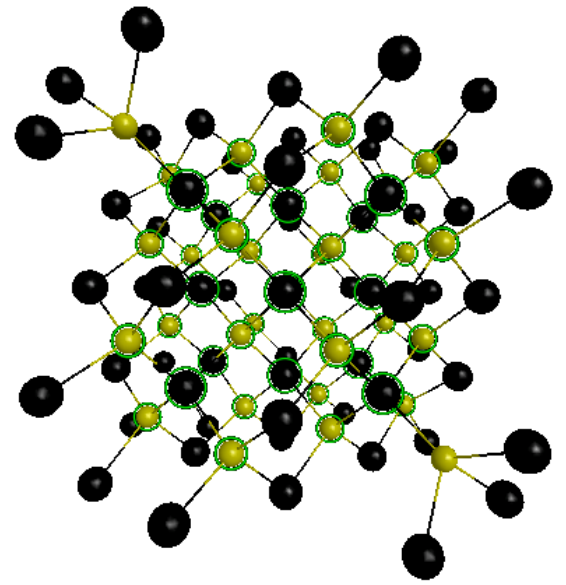

(b)

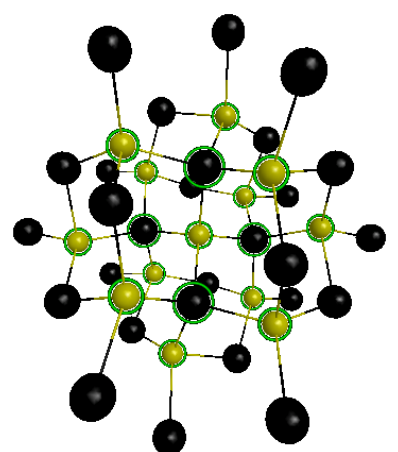

(d)

Figure S4. Side and top views of the $\mathrm{C} 3 \mathrm{i} \mathrm{Cd}_{62} \mathrm{~S}_{32}(\mathrm{a}, \mathrm{b})$ and $\mathrm{C} 2 \mathrm{i} \mathrm{Cd}_{28} \mathrm{~S}_{13}(\mathrm{c}, \mathrm{d})$ structures. The $\mathrm{C} 3 \mathrm{i} \mathrm{Cd}_{62} \mathrm{~S}_{32}$ has an anti-C2 $\mathrm{Cd}_{14} \mathrm{~S}_{28}$ core while the $\mathrm{C} 2 \mathrm{i} \mathrm{Cd}_{28} \mathrm{~S}_{13}$ has an anti-C1 $\left(\mathrm{Cd}_{4} \mathrm{~S}_{13}\right)$ core, respectively. Inner core $\mathrm{Cd}$ (black) and $\mathrm{S}$ (yellow) atoms are labeled with green circles. 


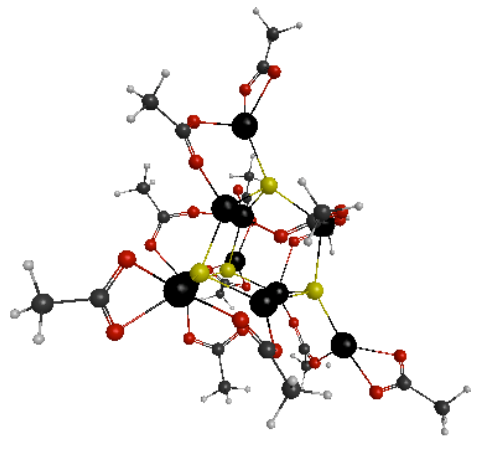

(a)

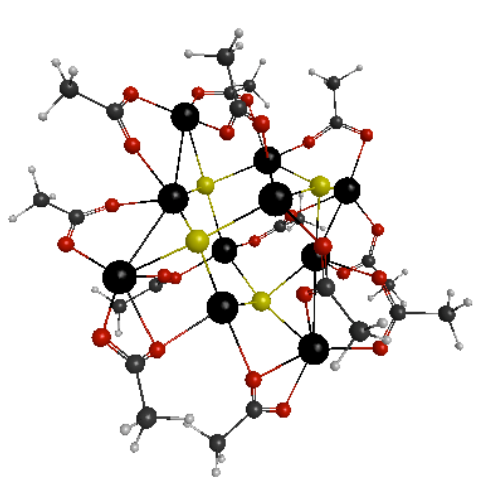

(d)

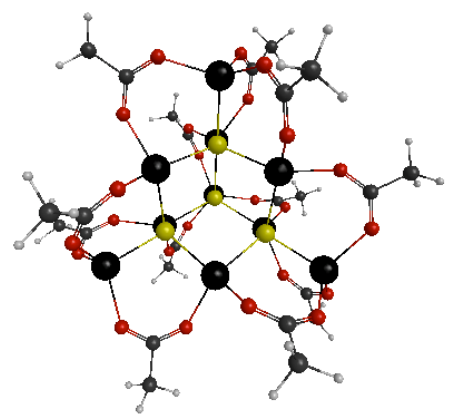

(g)

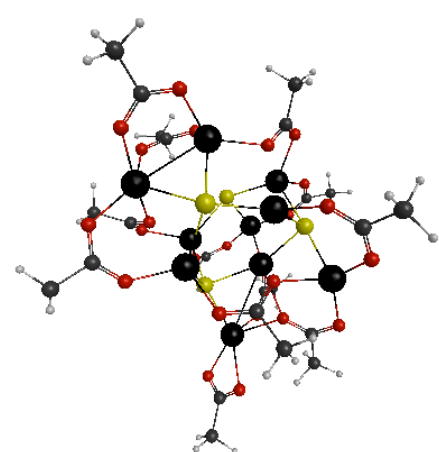

(b)

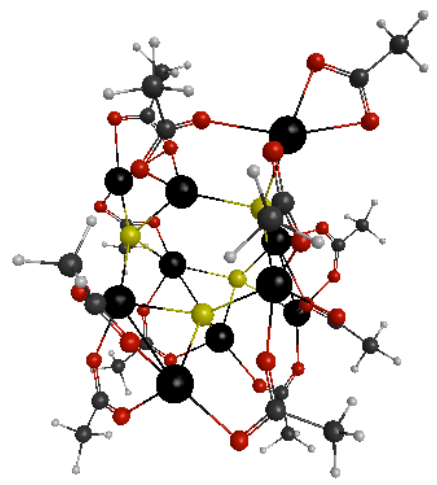

(e)

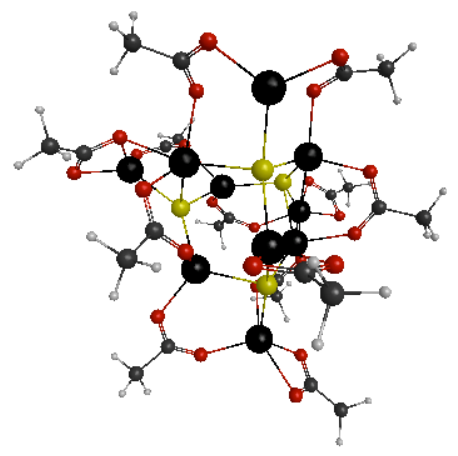

(c)

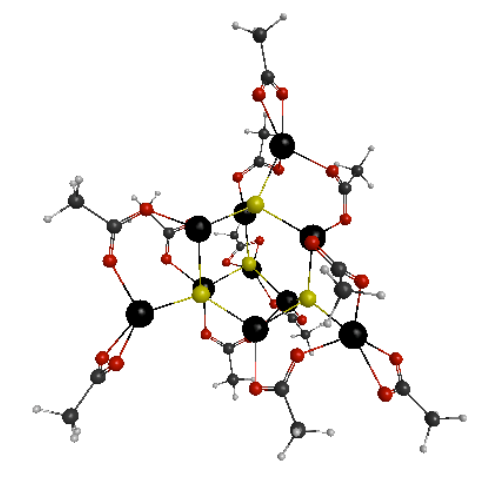

(f)

Figure S5. Computed PBE0-D3/SD-6-31G(d) structures for the $\mathrm{Cd}_{10} \mathrm{~S}_{4} \mathrm{X}_{12}(\mathrm{X}=$ acetate) cluster isomers. 

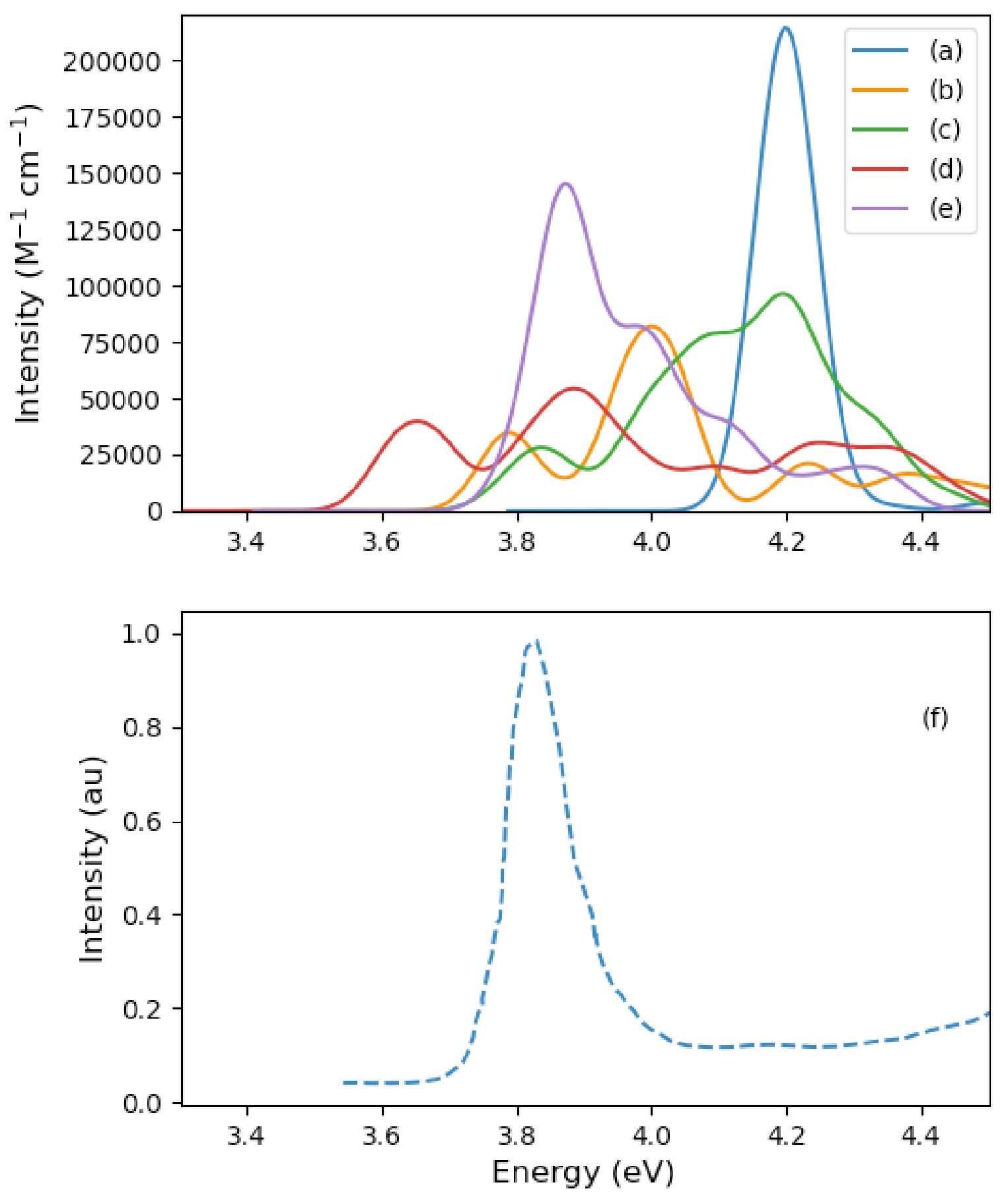

Figure S6. Computed electronic absorption spectra for the $\mathrm{Cd}_{28} \mathrm{~S}_{13} \mathrm{X}_{30}$ (a), $\mathrm{Cd}_{28} \mathrm{~S}_{14} \mathrm{X}_{28}$ (b), $\mathrm{Cd}_{35} \mathrm{~S}_{20} \mathrm{X}_{30}$ (c), $\mathrm{Cd}_{37} \mathrm{~S}_{20} \mathrm{X}_{34}$ (d) and $\mathrm{Cd}_{44} \mathrm{~S}_{26} \mathrm{X}_{36}$ (e) (X = acetate) clusters compared to the experimental spectrum (Williamson, C. B.; Nevers, D. R.; Nelson, A.; Hadar, I.; Banin, 622 U.; Hanrath, T.; Robinson, R. D. Chemically reversible isomerization 623 of inorganic clusters. Science 2019, 363 (6428), 731) of the $\alpha$-CdS cluster with oleate ligands (f). 